\title{
Potensi Pengembangan Komoditas Unggulan Tanaman Pangan Berdasarkan Analisis Location Quotient (LQ) di Kabupaten Langkat
}

\author{
Potential Development of Leading Food Crops Commodities Based on Location Quotient (LQ) \\ Analysis in Langkat Regency
}

Shabil Hidayat ${ }^{1}$, M.A. Girsang ${ }^{2}$, Sarman P. Tobing ${ }^{3}$, Khairiah $^{4}$, Lermansius Haloho ${ }^{5}$, P. Nainggolan ${ }^{6}$ ${ }_{1,2,3,4,5,6}$ Balai Pengkajian Teknologi Pertanian Sumatera Utara

\begin{abstract}
ARTICLE INFO
Article history:

DOI:

$\underline{10.30595 / p s p f s . v 2 i .211}$

Submitted:

July 29, 2021

Accepted:

Sept 10, 2021

Published:

Nov 10, 2021

ABSTRACT

This study aims to determine the superior-based food crops in Langkat Regency. This research is descriptive and analytical method. The type of data used in this study is secondary data based on data on land area and production of food crops (wet land paddy, dry land paddy, maize, cassava, sweet potato, soybeans, peanuts and green pea) in Langkat Regency and North Sumatra Province based on time series. in 2015-2019 (5 years). The results of the Location Quotient (LQ) analysis of Langkat Regency are different in each district. Where districts with $L Q \geq 1$ are the economic bases for certain commodities. And commodities with LQ value $<1$ are non-basic commodities, which means that certain plant products are not suitable for cultivation in the district. The results of the analysis showed that dry land paddy, cassava, sweet potatoes, peanuts, green beans and corn, where, dry land paddy reached 36,742 , cassava reached 30,149 , sweet potato 16,080 , peanuts 10,057 , green pea 9,910 , and maize reached 5,440.
\end{abstract}

Keywords:

Potency, Crops, Superior, LQ, Langkat

Corresponding Author:

Shabil Hidayat

Balai Pengkajian Teknologi Pertanian Sumatera Utara

Email: billoebis@yahoo.com
This work is licensed under a Creative Commons Attribution 4.0 International License.

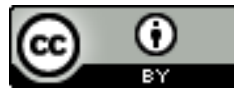

\section{PENDAhUluan}

Kabupaten Langkat yang terletak diantara $03^{\circ} 14^{\prime \circ}{ }^{\prime \prime}$ dan $04^{\circ} 13^{\prime}{ }^{\circ}$ ” Lintang Utara, serta $93^{\circ} 51^{\prime \circ}{ }^{\prime \prime}$ dan $98^{\circ} 45^{\circ 00}$ " Bujur Timur, tepatnya di sebelah utara Provinsi Sumatera Utara, memiliki luas wilayah $6.263,29 \mathrm{~km}^{2}$ atau $626.329 \mathrm{Ha}$, sekitar 8,74\% dari luas wilayah Provinsi Sumatera Utara, dengan batas-batas wilayah, yaitu : di sebelah Utara berbatas dengan selat Malaka dan Propinsi Nangro Aceh Darussalam, sebelah Selatan berbatas dengan Kabupaten Karo, sebelah Timur berbatas dengan Kabupaten Deli Serdang, sebelah Barat berbatas dengan Propinsi Nangro Aceh Darussalam. Memiliki iklim tropis dengan 2 musim, yaitu musim hujan dan musim kemarau, memiliki topografi yang sebagian merupakan dataran rendah, ada juga yang bergelombang, berbukit sampai dengan bergunung, dengan ketinggian antara $0 \mathrm{~m} \mathrm{dpl} \mathrm{s/d} 1.200 \mathrm{~m}$ dpl dengan garis pantai sepanjang $110 \mathrm{Km}$, dibedakan atas 3 bagian, yaitu Pesisir Pantai dengan ketinggian $0-4 \mathrm{~m}$ dpl, Dataran Rendah dengan ketinggian $0-30 \mathrm{~m}$ dpl, dan Dataran Tinggi dengan ketinggian $30-1200 \mathrm{~m}$ dpl.

Kabupaten Langkat terbagi dalam 3 Wilayah Pembangunan (WP) yaitu ; 1. Langkat Hulu seluas 211.029 ha, wilayah ini meliputi Kecamatan Bahorok, Kutambaru, Salapian, Sirapit, Kuala, Sei Bingai, Selesai dan Binjai. 2. Langkat Hilir seluas 250.761 ha. wilayah ini meliputi Kecamatan Stabat, Wampu, Secanggang, Hinai, Batang Serangan, Sawit Seberang, Padang Tualang dan Tanjung Pura, 3. Teluk Aru seluas 164.539 ha. wilayah 
ini meliputi Kecamatan Gebang, Babalan, Sei Lepan, Brandan Barat, Pangkalan Susu, Besitang dan Pematang Jaya.

Secara administratif, Kabupaten Langkat dengan Kota Stabat sebagai ibukotanya, terdiri atas 23 wilayah kecamatan, 240 desa, dan 37 kelurahan. Kecamatan dengan wilayah paling luas adalah Kecamatan Bahorok $1.101,83 \mathrm{~km}^{2}$ atau 17,59 persen, diikuti kecamatan Batang Serangan seluas $899,38 \mathrm{~km}^{2}$ atau 14,36 persen, dan yang paling sempit adalah Kecamatan Binjai yakni 42,05 km atau 0,67 persen dari total luas wilayah Kabupaten Langkat. Kecamatan dengan desa terbanyak adalah Kecamatan Bahorok dan Kecamatan Tanjung Pura (19 desa/kelurahan), sedangkan kecamatan dengan desa/kelurahan paling sedikit adalah Kecamatan Sawit Seberang, Brandan Barat dan Binjai (7 Desa/Kelurahan) (BPS 2020).

Kabupaten Langkat memiliki rencana kawasan pertanian, yakni kawasan tanaman lahan basah yang menyebar hampir di seluruh wilayah kecamatan baik dalam skala besar maupun kecil dengan luas total \pm 49.293 Ha. Kemudian kawasan tanaman lahan kering yang juga menyebar diseluruh kecamatan Kabupaten Langkat, baik dalam skala besar maupun kecil dengan luas total $36.348 \mathrm{Ha}$, dengan pusat pengembangan pertanian lahan kering meliputi Kecamatan Besitang, Bahorok, Hinai,Tanjung Pura, Sei Bingei, Binjai, Selesai, Wampu dan Secanggang. Juga kawasan tanaman tahunan/perkebunan yang diarahkan pada seluruh kecamatan dengan luas pengembangan mencapai $\pm 202.485 \mathrm{Ha}$.

Untuk potensi sektor pertanian tanaman pangan, berdasarkan data BPS 2020, Kabupaten Langkat memiliki produksi padi sawah sebesar 636.558 ton dengan luas panen 96.113 ha, produksi padi ladang 1.323 ton dengan luas panen 417 ha, untuk produksi jagung sebesar 133.387 ton dengan luas panen untuk jagung 18.145 ha, produksi ubi kayu15.613 ton dengan luas panen 414 ha, produksi ubi jalar sebesar 1.993 ton dengan luas panen 148 ha, produksi kedelai sebesar 2.598 ton dengan luasan panen 3.736 ha, produksi kacang tanah sebesar 417 ton dengan luasan panen 380 ha, produksi kacang hijau sebesar 901 ton dengan luasan panen kacang hijau 565 ha.

Pangan sebagai kebutuhan primer paling mendasar bagi manusia, sehingga ketahanan pangan sangat erat kaitannya dengan ketahanan sosial, stabilitas politik dan keamanan atau ketahanan nasional (Purwantini, et. al., 2003). Perlunya peningkatan ketahanan pangan dan pengembangan agribisnis menjadi program utama dalam pembangunan pertanian dan wilayah, karena berdasarkan Hasil Susenas Badan Pusat Statistik (2019), bahwa pengeluaran untuk pangan mencapai $49,21 \%$ dari total pengeluaran rumah rumah tangga, walaupun data tersebut memberikan fenomena pangsa pengeluaran pangan yang kurang dari 50 persen, yang mengindikasikan bahwa pengeluaran untuk bukan makanan penduduk Indonesia sedikit lebih besar porsinya dibandingkan untuk makanan, akan tetapi, apabila tercapainya ketahanan pangan yang merupakan salah satu bagian kerangka tujuan pembangunan berkelanjutan (Sustainable Development Goals/SDGs), maka juga mengakhiri kelaparan dan meningkatkan pertanian berkelanjutan (BKP, 2017).

Dalam usaha untuk meningkatkan ketahanan pangan wilayah dan pengembangan agribisnis secara simultan, kabupaten Langkat masih berpotensi dilakukan pengembangan komoditas pangan unggulan. Dengan diarahkan pada usaha pertanian berbasis sumberdaya domestik (unggulan daerah) yang permintaan produknya tidak elastis terhadap pendapatan maupun harga, sehingga tangguh menghadapi gejolak ekonomi (Krisnamurthi, 2002). Selain itu, produksi pertanian relatif stabil memiliki keterkaitan antara sektoral yang luas dan sangat penting untuk pemantapan ketahanan pangan (Wijaya. 2017). Oleh karena itu, penelitian ini bertujuan mengidentifikasi komoditas pangan unggulan wilayah sebagai dasar dalam menyusun strategi peningkatan ketahanan pangan berbasis komoditas unggulan.

Menurut Setiyanto (2013), komoditas unggulan adalah komoditas yang bukan saja sesuai dengan agroekologi setempat, tetapi juga harus memiliki daya saing, baik di tingkat lokal pasar daerah itu sendiri, tingkat nasional, bahkan di pasar internasional. komoditas tanaman pangan unggulan dan potensial dapat ditentukan dengan metode pendekatana analisis Location Quotient (LQ). Seperti yang dilakukan oleh Suharno (2012) dalam penelitiannya untuk menentukan keunggulan komparatif komoditas tanaman pangan berdasarkan LQ, melalui identifikasi dan potensi ekonomi pengembangan komoditas tanaman pangan unggulan dan potensial di Kabupaten Wonosobo, dan juga yang dilakukan oleh Sukmawani et al. (2014) dengan menentukan keunggulan komparatif dan kompetitif pepaya juga menggunakan analisis LQ, dalam model pengembangan komoditas pepaya sebagai komoditas unggulan lokal yang berdaya saing di Kabupaten Sukabumi.

\section{METODE PENELITIAN}

Penelitian dilakukan pada bulan Juni s/d November 2019, diawali mengolah data sekunder yang bersumber dari pemerintah daerah Kabupaten Langkat, Badan Pusat Statistik (BPS) Kabupaten Langkat, dan buku-buku referensi, kemudian dianalisis dengan menggunakan metode Analisis Location Quotient (LQ), untuk mengetahui komoditas unggulan (Miller dan Wright, 1991), dalam Darmawansyah (2003), yang ada pada suatu wilayah apakah termasuk ke dalam suatu basis atau non basis di kabupaten Langkat, dan metode yang sering dipakai untuk mengindikasi sektor basis yang kemudian selanjutnya digunakan untuk mengindikasi sektor unggulan adalah metode LQ (Sihombing, F.N. 2018.), sebagai tujuan dari penelitian ini. 


\section{Analisis data}

Menghitung LQ Produksi dan Luas Panen dengan memasukkan notasi-notasi yang diperoleh kedalam Rumus LQ, yaitu sebagai pembilang dan sebagai penyebut, atau dengan Rumus :

$L Q=\frac{p_{i} / p_{t}}{p_{i} / p_{t}}$

dimana:

LQ = Location Quotient

$\mathrm{Pi}=$ Produksi (luas panen ) jenis komoditas i pada tingkat kecamatan

$\mathrm{Pt}=$ Produksi (luas panen) tanaman pangan semua komoditas j pada tingkat kecamatan

$\mathrm{Pi}=$ Produksi (luas panen ) jenis komoditas i pada tingkat kabupaten

$\mathrm{Pt}=$ Produksi (luas panen) tanaman pangan komoditasi j pada tingkat kabupaten

Dengan ketentuan sebagai berikut:

LQ $>1$ menunjukkan terdapat konsentrasi relative disuatu wilayah dibandingkan dengan keseluruhan wilayah. Hal ini berarti komoditas i disuatu wilayah merupakan sektor basis yang berarti komoditas i di wilayah itu memiliki keunggulan komparatif.

LQ = 1 merupakan sektor non basis, artinya komoditas i disuatu wilayah tidak memiliki keunggulan komparatif. produksi komoditas yang dihasilkan hanya cukup untuk memenuhi kebutuhan sendiri dalam wilayah itu.

LQ $<1$ merupakan sektor non basis, artinya komoditas i disuatu wilayah tidak memiliki keunggulan komparatif, produksi komoditas i di wilayah itu tidak dapat memenuhi kebutuhan sendiri dan harus mendapat pasokan dari luar wilayah.

Komoditas yang menghasilkan nilai LQ > 1 merupakan strandar normative untuk ditetapkan sebagai komoditas unggulan. Dan jika banyak komoditas yang menghasilkan nilai LQ > 1 maka derajat keunggulan komparatif ditentukan berdasarkan nilai LQ yang lebih tinggi di suatu wilayah, karena makin tinggi nilai LQ maka menunjukkan semakin tinggi pula potensi keunggulan komoditas tersebut.

\section{HASIL DAN PEMBAHASAN}

Untuk mengkaji potensi tanaman pangan berdasarkan produksi di Kabupaten Langkat maka kita harus mengetahui produksi tanaman pangan di setiap kecamatan sehingga akan dihasilkan LQ perkecamatan setelah membandingkan dengan komoditas tanaman pangan di tingkat kabupaten.

Tabel 1. Produksi Tanaman Pangan di Kabupaten Langkat, Tahun 2018

\begin{tabular}{|c|c|c|c|c|c|c|c|c|c|c|}
\hline No & Kecamatan & $\begin{array}{c}\text { Padi } \\
\text { Sawah }\end{array}$ & $\begin{array}{c}\text { Padi } \\
\text { Ladang }\end{array}$ & Jagung & $\begin{array}{c}\text { Ubi } \\
\text { Kayu }\end{array}$ & $\begin{array}{l}\text { Ubi } \\
\text { Jalar }\end{array}$ & Kedelai & $\begin{array}{c}\text { Kacang } \\
\text { Tanah }\end{array}$ & $\begin{array}{c}\text { Kacang } \\
\text { Hijau }\end{array}$ & Total \\
\hline 1 & Bahorok & 12245 & 444 & 1677 & 430 & 39 & 0 & 46 & 0 & 14881 \\
\hline 2 & Serapit & 37267 & 343 & 8510 & 596 & 0 & 96,4 & 0 & 0 & 46812,4 \\
\hline 3 & Salapian & 2760 & 147 & 1711 & 0 & 195 & 0 & 9 & 2 & 4824 \\
\hline 4 & Kutambaru & 0 & 97 & 1448 & 35 & 0 & 0 & 2 & 0 & 1582 \\
\hline 5 & Sei Bingai & 63065 & 235 & 73653 & 385 & 351 & 0 & 21 & 0 & 137710 \\
\hline 6 & Kuala & 16651 & 27 & 5680 & 2666 & 203 & 117,75 & 0 & 9 & 25353,75 \\
\hline 7 & Selesai & 26359 & 30 & 22844 & 841 & 0 & 73,25 & 56 & 22 & 50225,25 \\
\hline 8 & Binjai & 26000 & 0 & 1309 & 400 & 81 & 185,13 & 149 & 42 & 28166,13 \\
\hline 9 & Stabat & 22231 & 0 & 5365 & 1093 & 309 & 342,93 & 13 & 275 & 29628,93 \\
\hline 10 & Wampu & 17991 & 0 & 1718 & 90 & 13 & 157,37 & 8 & 3 & 19980,37 \\
\hline 11 & Batang Serangan & 1756 & 0 & 0 & 0 & 67 & 0 & 1 & 0 & 1824 \\
\hline 12 & Sawit Seberang & 0 & 0 & 312 & 456 & 0 & 0 & 0 & 0 & 768 \\
\hline 13 & Padang Tualang & 1610 & 0 & 31 & 385 & 0 & 0 & 3 & 7 & 2036 \\
\hline 14 & Hinai & 26605 & 0 & 860 & 1795 & 65 & 328,20 & 19 & 338 & 30010,2 \\
\hline 15 & Secanggang & 84324 & 0 & 3453 & 2312 & 244 & 996,26 & 54 & 79 & 91462,26 \\
\hline 16 & Tanjung Putra & 60547 & 0 & 626 & 2155 & 161 & 8,21 & 18 & 66 & 63581,21 \\
\hline 17 & Gebang & 32479 & 0 & 829 & 0 & 0 & 8,32 & 0 & 0 & 33316,32 \\
\hline 18 & Babalan & 71853 & 0 & 0 & 26 & 0 & 23,14 & 0 & 0 & 71902,14 \\
\hline 19 & Sei Lepan & 27681 & 0 & 241 & 0 & 0 & 68,64 & 0 & 0 & 27990,64 \\
\hline
\end{tabular}

Proceedings homepage: https://conferenceproceedings.ump.ac.id/index.php/pspfs/issue/view/9 


\begin{tabular}{rcrrrrrrrrr}
\hline 20 & Brandan Barat & 23646 & 0 & 0 & 214 & 0 & 61,94 & 0 & 0 & 23921,94 \\
21 & Besitang & 23742 & 0 & 1010 & 1141 & 186 & 130,2 & 9 & 12 & 26230,2 \\
22 & Pangkalan Susu & 44351 & 0 & 245 & 223 & 0 & 0 & 0 & 0 & 44819 \\
23 & Pematang Jaya & 13395 & 0 & 1865 & 370 & 79 & 0 & 9 & 46 & 15764 \\
\hline & Total & 636558 & 1323 & 133387 & 15613 & 1993 & 2597,74 & 417 & 901 & 792789,7 \\
\hline
\end{tabular}

Dari total produksi tanaman pangan Kabupaten Langkat komoditi padi sawah 636.558 ton adalah berasal dari produksi kecamatan Secanggang sebesar 84.324 ton dan merupakan kecamatan produksi paling tinggi dan diikuti kecamatan Babalan 71.853 ton dan kecamatan terendah Padang Tualang 1610 ton. Akan tetapi untuk padi ladang produksi kecamatan Bahorok lebih tinggi 444 ton, diikuti kecamatan Sirapit, Sei Bingai sampai ke kecamatan produksi terendah Kuala 27 ton.

Untuk produksi jagung, kecamatan Sei Bingai 73653 ton, Selesai 22844 ton dengan total produksi 133.387 ton. Demikian juga dengan komoditi ubi kayu dan ubi jalar, kedelai juga kacang, produksi tertinggi masing-masing komoditas juga berada pada kecamatan yang berbeda-beda. Dalam hal ini setiap kecamatan memiliki keungulan tersendiri untuk berproduksi.

Berdasarkan hasil analisa basis produksi dengan metode LQ pada tahun 2019 maka lokasi yang merupakan basis pengembangan sub sektor tanaman pangan di kabupaten Langkat adalah kecamatan Bahorok, di mana komoditi padi sawah, padi ladang ubi kayu, ubi jalar dan kacang tanah memiliki potensi produksi karena nilai LQnya lebih besar dari satu, akan tetapi untuk komoditi jagung tidak berpotensi dikembangkan karena nilai LQnya lebih kecil dari satu yaitu untuk jagung 0,670; untuk kedelai 0 dan untuk kacang hijau 0.

Tabel 2. Hasil analisis Nilai Location Quotient (LQ) terhadap produksi tanaman pangan Kabupaten Langkat

\begin{tabular}{clrrrrrrrr}
\hline \multirow{2}{*}{ No } & Kecamatan & $\begin{array}{c}\text { Padi } \\
\text { Sawah }\end{array}$ & $\begin{array}{c}\text { Padi } \\
\text { Ladang }\end{array}$ & Jagung & $\begin{array}{c}\text { Ubi } \\
\text { Kayu }\end{array}$ & $\begin{array}{c}\text { Ubi } \\
\text { Jalar }\end{array}$ & Kedelai & $\begin{array}{c}\text { Kacang } \\
\text { Tanah }\end{array}$ & $\begin{array}{c}\text { Kacang } \\
\text { Hijau }\end{array}$ \\
\hline 1 & Bahorok & $\mathbf{1 , 0 2 5}$ & $\mathbf{1 7 , 8 7 9}$ & 0,670 & $\mathbf{1 , 4 6 7}$ & $\mathbf{1 , 0 4 3}$ & 0,000 & $\mathbf{5 , 8 7 7}$ & 0,000 \\
2 & Serapit & 0,991 & $\mathbf{4 , 3 9 1}$ & $\mathbf{1 , 0 8 0}$ & 0,646 & 0,000 & 0,628 & 0,000 & 0,000 \\
3 & Salapian & 0,713 & $\mathbf{1 8 , 2 6 0}$ & $\mathbf{2 , 1 0 8}$ & 0,000 & $\mathbf{1 6 , 0 8 0}$ & 0,000 & $\mathbf{3 , 5 4 7}$ & 0,365 \\
4 & Kutambaru & 0,000 & $\mathbf{3 6 , 7 4 2}$ & $\mathbf{5 , 4 4 0}$ & $\mathbf{1 , 1 2 3}$ & 0,000 & 0,000 & $\mathbf{2 , 4 0 4}$ & 0,000 \\
5 & Sei Bingai & 0,570 & $\mathbf{1 , 0 2 3}$ & $\mathbf{3 , 1 7 9}$ & 0,142 & $\mathbf{1 , 0 1 4}$ & 0,000 & 0,290 & 0,000 \\
6 & Kuala & 0,818 & 0,638 & $\mathbf{1 , 3 3 2}$ & $\mathbf{5 , 3 3 9}$ & $\mathbf{3 , 1 8 5}$ & $\mathbf{1 , 4 1 7}$ & 0,000 & 0,312 \\
7 & Selesai & 0,654 & 0,358 & $\mathbf{2 , 7 0 3}$ & 0,850 & 0,000 & 0,445 & $\mathbf{2 , 1 2 0}$ & 0,385 \\
8 & Binjai & $\mathbf{1 , 1 5 0}$ & 0,000 & 0,276 & 0,721 & $\mathbf{1 , 1 4 4}$ & $\mathbf{2 , 0 0 6}$ & $\mathbf{1 0 , 0 5 7}$ & $\mathbf{1 , 3 1 2}$ \\
9 & Stabat & 0,934 & 0,000 & $\mathbf{1 , 0 7 6}$ & $\mathbf{1 , 8 7 3}$ & $\mathbf{4 , 1 4 9}$ & $\mathbf{3 , 5 3 2}$ & 0,834 & $\mathbf{8 , 1 6 7}$ \\
10 & Wampu & $\mathbf{1 , 1 2 1}$ & 0,000 & 0,511 & 0,229 & 0,259 & $\mathbf{2 , 4 0 4}$ & 0,761 & 0,132 \\
11 & Batang Serangan & $\mathbf{1 , 1 9 9}$ & 0,000 & 0,000 & 0,000 & $\mathbf{1 4 , 6 1 2}$ & 0,000 & $\mathbf{1 , 0 4 2}$ & 0,000 \\
12 & Sawit Seberang & $\mathbf{0 , 0 0 0}$ & 0,000 & $\mathbf{2 , 4 1 5}$ & $\mathbf{3 0 , 1 4 9}$ & 0,000 & 0,000 & 0,000 & 0,000 \\
13 & Padang Tualang & 0,985 & 0,000 & 0,090 & $\mathbf{9 , 6 0 2}$ & 0,000 & 0,000 & $\mathbf{2 , 8 0 1}$ & $\mathbf{3 , 0 2 5}$ \\
14 & Hinai & $\mathbf{1 , 1 0 4}$ & 0,000 & 0,170 & $\mathbf{3 , 0 3 7}$ & 0,862 & $\mathbf{3 , 3 3 8}$ & $\mathbf{1 , 2 0 4}$ & $\mathbf{9 , 9 1 0}$ \\
15 & Secanggang & $\mathbf{1 , 1 4 8}$ & 0,000 & 0,224 & $\mathbf{1 , 2 8 4}$ & $\mathbf{1 , 0 6 1}$ & $\mathbf{3 , 3 2 4}$ & $\mathbf{1 , 1 2 2}$ & 0,760 \\
16 & Tanjung Putra & $\mathbf{1 , 1 8 6}$ & 0,000 & 0,059 & $\mathbf{1 , 7 2 1}$ & $\mathbf{1 , 0 0 7}$ & 0,039 & 0,538 & 0,913 \\
17 & Gebang & $\mathbf{1 , 2 1 4}$ & 0,000 & 0,148 & 0,000 & 0,000 & 0,076 & 0,000 & 0,000 \\
18 & Babalan & $\mathbf{1 , 2 4 5}$ & 0,000 & 0,000 & 0,018 & 0,000 & 0,098 & 0,000 & 0,000 \\
19 & Sei Lepan & $\mathbf{1 , 2 3 2}$ & 0,000 & 0,051 & 0,000 & 0,000 & 0,748 & 0,000 & 0,000 \\
20 & Brandan Barat & $\mathbf{1 , 2 3 1}$ & 0,000 & 0,000 & 0,454 & 0,000 & 0,790 & 0,000 & 0,000 \\
21 & Besitang & $\mathbf{1 , 1 2 7}$ & 0,000 & 0,229 & $\mathbf{2 , 2 0 9}$ & $\mathbf{2 , 8 2 1}$ & $\mathbf{1 , 5 1 5}$ & 0,652 & 0,403 \\
22 & Pangkalan Susu & $\mathbf{1 , 2 3 2}$ & 0,000 & 0,032 & 0,253 & 0,000 & 0,000 & 0,000 & 0,000 \\
23 & Pematang Jaya & $\mathbf{1 , 0 5 8}$ & 0,000 & 0,703 & $\mathbf{1 , 1 9 2}$ & $\mathbf{1 , 9 9 3}$ & 0,000 & $\mathbf{1 , 0 8 5}$ & $\mathbf{2 , 5 6 8}$ \\
\hline
\end{tabular}

Selain kecamatan Bahorok, kecamatan yang berpeluang dikembangkan adalah kecamatan Serapit untuk komoditi padi ladang 4,391 dan jagung 1,080, akan tetapi komoditi padi sawah di daerah ini tidak berpotensi karena nilai LQnya lebih kecil dari satu yaitu 0,991 .

Semua kecamatan di kabupaten Langkat berdasarkan analisis basis produksi dengan metode LQ berpeluang dikembangkan untuk komoditi tertentu. Lokasi yang berpeluang untuk pengembangan padi sawah misalnya adalah Bahorok, Binjai, Wampu, Batang Serangan, Hinai, Secanggang, Tanjung Putra, Gebang, Babalan, Sei Lepan, Brandan barat, Besitang, Pangkalan susu dan Pematang jaya. Lokasi pengembangan untuk jagung adalah Serapit, Salapian, Kutambaru Sei bingai, Kuala, Selesai, Stabat, dan Sawit seberang. Lokasi pengembangan untuk kedelai adalah Kuala, Binjai, Stabat, Wampu, Hinai, Secanggang dan Besitang.

Dari hasil analisis basis luas panen dengan metode LQ maka yang menjadi kecamatan yang berpotensi untuk pengembangan padi sawah adalah kecamatan Binjai $(1,099)$, Hinai $(1,071)$, Secanggang $(1,177)$, Tanjung 
Putra (1,244), Gebang (1,267), Babalan (1,306), Sei Lepan (1,280), Brandan Barat $(1,240)$, Besitang $(1,085)$, Pangkalan Susu $(1,256)$ dan Pematang Jaya $(1,225)$, di mana nilai LQ dari masing-masing kecamatan lebih besar satu, sedangkan kecamatan Bahorok, Sirapit dan yang lain, tidak memiliki potensi pengembangan disebabkan nilai LQnya lebih kecil satu.

Tabel 3. Hasil analisis Nilai Location Quotient (LQ) terhadap luas panen tanaman pangan Kabupaten Langkat

\begin{tabular}{clcccccccc}
\hline \multirow{2}{*}{ No } & Kecamatan & $\begin{array}{c}\text { Padi } \\
\text { Sawah }\end{array}$ & $\begin{array}{c}\text { Padi } \\
\text { Ladang }\end{array}$ & Jagung & $\begin{array}{c}\text { Ubi } \\
\text { Kayu }\end{array}$ & $\begin{array}{c}\text { Ubi } \\
\text { Jalar }\end{array}$ & Kedelai & $\begin{array}{c}\text { Kacang } \\
\text { Tanah }\end{array}$ & $\begin{array}{c}\text { Kacang } \\
\text { Hijau }\end{array}$ \\
\hline 1 & Bahorok & 0,896 & $\mathbf{1 1 , 3 8 5}$ & $\mathbf{1 , 2 5 6}$ & $\mathbf{1 , 2 5 7}$ & 0,619 & 0,055 & $\mathbf{2 , 3 4 0}$ & 0,000 \\
2 & Serapit & 0,852 & $\mathbf{1 , 4 1 5}$ & $\mathbf{1 , 6 6 7}$ & 0,000 & 0,000 & $\mathbf{2 , 4 1 6}$ & 0,473 & 0,439 \\
3 & Salapian & 0,478 & $\mathbf{9 , 3 8 2}$ & $\mathbf{2 , 1 5 5}$ & $\mathbf{6 , 7 9 4}$ & $\mathbf{6 , 7 6 7}$ & 0,000 & $\mathbf{5 , 8 7 7}$ & 0,000 \\
4 & Kutambaru & 0,000 & $\mathbf{5 3 , 4 9 9}$ & $\mathbf{2 , 9 6 5}$ & $\mathbf{1 3 , 0 8 2}$ & $\mathbf{5 , 1 2 4}$ & 0,000 & $\mathbf{2 , 2 7 1}$ & 0,720 \\
5 & Sei Bingai & 0,664 & $\mathbf{1 , 5 7 0}$ & $\mathbf{2 , 3 7 5}$ & 0,137 & 0,583 & 0,000 & 0,170 & 0,000 \\
6 & Kuala & 0,780 & $\mathbf{2 , 9 2 3}$ & $\mathbf{1 , 5 2 1}$ & $\mathbf{2 , 8 0 0}$ & $\mathbf{6 , 2 8 5}$ & 0,000 & $\mathbf{2 , 4 1 7}$ & $\mathbf{1 , 7 5 8}$ \\
7 & Selesai & 0,655 & 0,000 & $\mathbf{2 , 3 6 5}$ & 0,623 & 0,000 & 0,428 & $\mathbf{1 , 4 8 2}$ & 0,020 \\
8 & Binjai & $\mathbf{1 , 0 9 9}$ & $\mathbf{1 , 9 6 1}$ & 0,598 & 0,433 & $\mathbf{1 , 7 6 9}$ & $\mathbf{3 , 7 2 3}$ & $\mathbf{3 , 4 7 3}$ & $\mathbf{1 , 1 8 2}$ \\
9 & Stabat & 0,759 & 0,000 & $\mathbf{1 , 2 7 1}$ & $\mathbf{5 , 7 0 1}$ & $\mathbf{3 , 6 7 5}$ & $\mathbf{3 , 9 1 0}$ & $\mathbf{4 , 9 3 4}$ & $\mathbf{9 , 3 5 5}$ \\
10 & Wampu & 0,721 & 0,000 & $\mathbf{2 , 1 1 4}$ & 0,415 & 0,000 & $\mathbf{6 , 8 2 9}$ & 0,000 & 0,000 \\
11 & Batang Serangan & 0,645 & 0,000 & $\mathbf{2 , 3 1 1}$ & $\mathbf{1 , 6 5 6}$ & 0,000 & 0,000 & $\mathbf{1 , 2 8 4}$ & 0,000 \\
12 & Sawit Seberang & 0,000 & 0,000 & $\mathbf{1 , 2 8 8}$ & $\mathbf{3 5 , 6 1 2}$ & $\mathbf{7 , 9 7 3}$ & 0,000 & $\mathbf{4 , 0 7 2}$ & $\mathbf{1 , 9 4 6}$ \\
13 & Padang Tualang & 0,996 & 0,000 & 0,443 & $\mathbf{7 , 3 9 4}$ & 0,000 & 0,000 & 0,797 & $\mathbf{1 , 1 1 9}$ \\
14 & Hinai & $\mathbf{1 , 0 7 1}$ & 0,000 & 0,582 & 0,969 & $\mathbf{1 , 6 4 8}$ & $\mathbf{8 , 1 9 8}$ & $\mathbf{2 , 1 5 2}$ & $\mathbf{1 1 , 6 3 5}$ \\
15 & Secanggang & $\mathbf{1 , 1 7 7}$ & 0,000 & 0,398 & 0,598 & 0,890 & 0,120 & 0,954 & 0,431 \\
16 & Tanjung Putra & $\mathbf{1 , 2 4 4}$ & 0,000 & 0,068 & $\mathbf{1 , 4 6 2}$ & 0,962 & 0,281 & 0,451 & 0,345 \\
17 & Gebang & $\mathbf{1 , 2 6 7}$ & 0,000 & 0,132 & 0,220 & 0,000 & 0,000 & 0,000 & 0,000 \\
18 & Babalan & $\mathbf{1 , 3 0 6}$ & 0,000 & 0,000 & 0,032 & 0,051 & 0,000 & 0,000 & 0,000 \\
19 & Sei Lepan & $\mathbf{1 , 2 8 0}$ & 0,000 & 0,101 & 0,000 & 0,000 & 0,000 & 0,000 & 0,000 \\
20 & Brandan Barat & $\mathbf{1 , 2 4 0}$ & 0,000 & 0,231 & 0,245 & 0,000 & 0,000 & 0,000 & 0,000 \\
21 & Besitang & $\mathbf{1 , 0 8 5}$ & 0,000 & 0,548 & 2,654 & $\mathbf{1 , 0 3 0}$ & 0,399 & 0,746 & 0,094 \\
22 & Pangkalan Susu & $\mathbf{1 , 2 5 6}$ & 0,000 & 0,180 & 0,058 & 0,420 & 0,000 & 0,000 & 0,051 \\
23 & Pematang Jaya & $\mathbf{1 , 2 2 5}$ & 0,000 & 0,067 & $\mathbf{1 , 4 5 3}$ & $\mathbf{2 , 6 8 9}$ & 0,000 & $\mathbf{2 , 9 8 1}$ & $\mathbf{1 , 1 2 2}$ \\
\hline & & & & & & &
\end{tabular}

Potensi pengembangan komoditi kedelai adalah berada di kecamatan Serapit, Binjai, Setabat, Wampu, dan Hinai, sedangkan kecamatan lain yang nilai LQnya dibawah satu tidak potensi untuk pengembangan kedelai.

\section{KESIMPULAN}

Semua kecamatan di kabupaten Langkat berdasarkan analisis basis dengan metode LQ Location Quotient berpeluang dikembangkan untuk komoditi padi sawah. Dan komoditi tanaman unggulan di kabupaten Langkat adalah padi ladang, ubi kayu, ubi jalar, kacang tanah, kacang hijau dan jagung.

\section{DAFTAR PUSTAKA}

Badan Ketahanan Pangan Nasional 2017.

BPS Hasil Susenas 2019 Pengeluaran Untuk Konsumsi Penduduk Indonesia Per Provinsi.

Badan Pusat Statistik Provinsi Sumatera Utara. 2016. Kabupaten Langkat Dalam Angka 2015. Badan Pusat Statistik Provinsi Sumatera Utara.

Badan Pusat Statistik Provinsi Sumatera Utara. 2017. Kabupaten Langkat Dalam Angka 2016. Badan Pusat Statistik Provinsi Sumatera Utara.

Badan Pusat Statistik Provinsi Sumatera Utara. 2018. Kabupaten Langkat Dalam Angka 2017. Badan Pusat Statistik Provinsi Sumatera Utara.

Badan Pusat Statistik Provinsi Sumatera Utara. 2019. Kabupaten Langkat Dalam Angka 2018. Badan Pusat Statistik Provinsi Sumatera Utara.

Badan Pusat Statistik Provinsi Sumatera Utara. 2020. Kabupaten Langkat Dalam Angka 2019. Badan Pusat Statistik Provinsi Sumatera Utara.

Creswell, J. W. 2010. Research design: pendekatan kualitatif, kuantitatif, dan mixed. Yogjakarta: PT Pustaka Pelajar. 
Darmawansyah.2003. Pengembangan Komoditi Unggulan Sebagai Basis Ekonomi Daerah. Tesis S-2 Program Pasca Sarjana IPB. Bogor.

Kerlinger. 2006. Asas-Asas Penelitian Behaviour. Edisi 3, Cetakan 7. Yogyakarta: Gadjah Mada University Press.

Krisnamurthi, Bayu, . (2002). Membangun Koperasi Berbasis Anggota Dalam Rangka Pengembangan Ekonomi Rakyat. Jurnal Ekonomi Rakyat, I, 4.

Miller, M.M., Gibson, J.L., \& Wright, G.N. 1991. Location Quotient Basic Tool for Economic Development Analysis. Economic Development Review. 9(2), 65.

Purwantini, T. B., Ariani, M., \& Marisa, Y. 2003. Analisis Kerawanan Pangan Wilayah dalam Perspektif Desentralisasi Pembangunan. Bogor: Pusat Analisis Sosial Ekonomi dan Kebijakan Pertanian.

Setiyanto, A. 2013. Pendekatan dan Implementasi Pengembangan Kawasan Komoditas Unggulan Pertanian. Forum Penelitian Agro Ekonomi 31 (2): 71-195.

Sihombing, F.N. 2018. Identifikasi Pangan Unggulan Di Kota Medan : Location Quotient Dan Dynamic Location Quotient. Jurnal Pembangunan Perkotaan, 6 (2) : 91-94.

Suharno. 2012. Identifikasi dan Potensi Ekonomi Pengembangan Komoditas Tanaman Pangan Unggulan dan Potensial di Kabupaten Wonosobo. Media Ekonomi dan Manajemen 26(2):34-41.

Sukmawani, R., M. Haeruman, L. Sulistyowati, dan T. Perdana. 2014. Model Pengembangan Pepaya Sebagai Komoditas Unggulan Lokal yang Berdaya Saing. Jurnal Ekonomi Pembangunan 15(2):128-140.

Wijaya, Oki. 2017. Strategi Pengembangan Komoditas Pangan Unggulan dalam Menunjang Ketahanan Pangan Wilayah (Studi Kasus di Kabupaten Batang, Propinsi Jawa Tengah). AGRARIS, Vol. 3 (1). Januari. pp. 48-56. http://DOI: 10.18196/agr.3144. 